\title{
Attentional agency and the implementation of a strategic initiative
}

\author{
Keil, Thomas ; Schmidt, Jens
}

\begin{abstract}
We report findings from an in-depth single case study about a failed new venture initiative in a large firm that suggest that attentional agency (i.e. the exercise of discretion by managers over the distribution and allocation of attention of other organizational members) and the incompleteness of governance channels (i.e. the formal and informal mechanisms set up by managers to provide the necessary information to guide their attention) are key determinants of the distribution of organizational attention and behavior of organizational members. Our findings demonstrate the central role of individual discretion, as opposed to structural determinism, to organizational attention and behavior. They also suggest that attentional agency and incomplete governance channels may lead to incoherence in the implementation of a strategic initiative as well as a drift away from initial scope and objectives and languishing of the initiative, which may be countered by a focus on quality of attention. Finally, they highlight the crucial role of the quality of top management attention, rather than top management support per se, in determining the performance of a corporate venture.
\end{abstract}

Posted at the Zurich Open Repository and Archive, University of Zurich

ZORA URL: https://doi.org/10.5167/uzh-110926

Conference or Workshop Item

Presentation

Originally published at:

Keil, Thomas; Schmidt, Jens (2015). Attentional agency and the implementation of a strategic initiative. In: The Annual Meeting of the Academy of Management, Vancouver, Canada, 7 August 2015 - 11 August 2015. s.n., online. 
ATTENTIONAL AGENCY, INCOMPLETE GOVERNANCE CHANNELS, AND THE IMPLEMENTATION OF A STRATEGIC INITIATIVE

\author{
Jens Schmidt \\ Aalto University \\ Thomas Keil \\ University of Zurich
}

Paper to be presented at the Academy of Management Conference 2015

Submission ID 18440 


\begin{abstract}
We report findings from an in-depth single case study about a failed new venture initiative in a large firm that suggest that attentional agency (i.e. the exercise of discretion by managers over the distribution and allocation of attention of other organizational members) and the incompleteness of governance channels (i.e. the formal and informal mechanisms set up by managers to provide the necessary information to guide their attention) are key determinants of the distribution of organizational attention and behavior of organizational members. Our findings demonstrate the central role of individual discretion, as opposed to structural determinism, to organizational attention and behavior. They also suggest that attentional agency and incomplete governance channels may lead to incoherence in the implementation of a strategic initiative as well as a drift away from initial scope and objectives and languishing of the initiative, which may be countered by a focus on quality of attention. Finally, they highlight the crucial role of the quality of top management attention, rather than top management support per se, in determining the performance of a corporate venture.
\end{abstract}


Administration is orderly discussed as the art of "getting things done"

(Simon, 1947, p. 7)

The fact that goals may be dependent for their force on other more distant ends leads to the arrangement of these goals in a hierarchy-each level to be considered as an end relative to the levels above it. Through the hierarchical structure of ends, behavior attains integration and consistency, for each member of a set of behavior alternatives is then weighed in terms of a comprehensive scale of "values" -the "ultimate" ends. In actual behavior, a high degree of conscious integration is seldom attained. Instead of a single branching hierarchy, the structure of conscious motives is usually a tangled web or, more precisely, a disconnected collection of elements only weakly and incompletely tied together; and the integration of these elements becomes progressively weaker as the higher levels of the hierarchy - the more final ends-are reached.

(Simon, 1947, p. 73)

\section{INTRODUCTION}

The long-term performance and survival of organizations depends on the question whether they are able to successfully implement strategic initiatives, independent of whether these originate from top-down, deliberate decisions made by top management or from bottom-up, emergent activities championed by middle managers (Bower, 1970; Burgelman, 1983). Implementation is premised on setting desired outcomes for the initiative, but the means by which these outcomes should be achieved are typically only imperfectly specified at the outset (Cyert \& March, 1963; Klingebiel \& De Meyer, 2012; Pitsis, Clegg, Marosszeky, \& Rura-Polley, 2003). This leaves organizational members with a variety of choices to be made in implementing the initiative (Klingebiel \& De Meyer, 2012). Building on Simon (1947), Ocasio (1997) argues in his attention-based view of strategic management that how such choices are made is largely driven by how the organization distributes stimuli to organizational members that drive their attention to particular issues and answers. This 
structural perspective on attention has been further corroborated by Joseph and Ocasio (2012) in their study of the organizational architecture at General Electric. Yet, it downplays the role of individuals that were central to Simon's (1947) work in favor of structural determinism. Specifically, it takes as given that alignment between organizational members has been attained both in terms of goals and in terms of understanding.

In this article we report findings from a single in-depth case study that suggest that the role of structure in distributing attention and thereby determining organizational behavior as put forth by Ocasio (1997) may be overstated. In that study, we followed a strategic initiative in the form of a new venture over a period of four years, after which the initiative was shut down because it failed to achieve its objectives. Our data cover four levels of the organizational hierarchy and provide deep insights into the decision-making about and the attention devoted to the initiative by organizational members.

We found that, in conflict with Ocasio's (1997) argument, attention was essentially underdetermined by structure and individuals used substantial discretion in making decisions (Felin \& Foss, 2011; Levinthal \& Rerup, 2006), leaving room for “attentional agency”, i.e. the exercise of discretion by managers over the distribution and allocation of attention of other organizational members. Furthermore the "governance channels", i.e. the formal and informal mechanisms set up by managers to provide the necessary information to guide their attention, turned out to be incomplete, i.e. the decision-makers at higher levels of the organization were essentially misinformed about the true state of the initiative. The interplay of attentional agency and incomplete governance channels led to incoherencies between the original strategic decision and the scope and objectives of the initiative and decisions made at lower levels remaining unresolved. Over time this led to a situation where the issues and answers that were available to organizational members were based on prior instances of discretion by other individuals as well as the way governance channels had been created by 
superiors and exploited by managers at lower levels. Furthermore, it also led to the endogenous generation of new issues and answers to deal with the problems generated by attentional agency and incomplete governance channels. Our findings thus suggest that there is a strong role for individual agency at all levels of the hierarchy in the distribution of organizational attention (Emirbayer \& Mische, 1998; Heugens \& Lander, 2009) and that the role of individuals may be important in accounting for organizations' ability to adapt to environmental changes (Ocasio, 1997).

We also find that attentional agency and incomplete governance channels not only pose limits to the coherence of lower-level decisions with the original scope and objectives of a strategic initiative, but that they may lead to a situation where managers at higher levels of the hierarchy may not be able to distinguish between the involuntary drift of an initiative away from its original scope and objectives on the one hand and beneficial adaptation due to learning on the other hand (Siggelkow \& Rivkin, 2009). This may lead to strategic initiatives languishing and, rather than being terminated because of failing to reach its objectives, being sustained and even receive additional funding, which provides for an alternative explanation for why firms fail to terminate failing initiatives (Ross \& Staw, 1986; Sleesman, Conlon, McNamara, \& Miles, 2012). To solve these problems, strategic initiatives may require not only the allocation of sufficient attention among higher-level managers (what Ocasio (2011) calls "attentional engagement"), but even more importantly that attention needs to be of high quality (Weick \& Sutcliffe, 2006).

Our article makes contributions to three literatures. First and foremeost, we add to the literature on organizational attention (Joseph \& Ocasio, 2012; Ocasio, 1999, 2011) by demonstrating the central role of individuals to organizational attention and behavior, in particular by highlighting how attentional agency and incomplete governance channels lead to the distribution of attention and the availability (and even endogenous generation) of issues 
and answers. Second, we add to the literature on strategic initatives (Klingebiel \& De Meyer, 2012; Lechner \& Floyd, 2012) by showing how attentional agency and incomplete governance channels may lead to incoherence in the implementation of a strategic initiative as well as drift and languishing of the initiative, which may be countered by a focus on quality of attention. Third, we contribute to the literature on corporate venture failure (Keil, McGrath, \& Tukiainen, 2009; Thornhill \& Amit, 2003) by highlighting the crucial role of the quality of top management attention, rather than top management support per se, to the performance of a corporate venture.

\section{BACKGROUND}

\section{Attention, structure and adaptation}

A growing body of work in the management literature examines the role of attention, defined as "noticing, encoding, interpreting, and focusing of time and effort by organizational decision-makers on both (a) issues [...] and (b) answers" (Ocasio, 1997: 189), in achieving strategic outcomes such as adaptation to a changing environment. The study of attention follows Simon's $(1947,1996)$ insights concerning the cognitive limits imposed on organizational members in combination with environmental complexity that require them to be selective in terms of where to allocate their scarce cognitive resources. As Simon (1947) noted, decisions made by organizational members are initiated by "stimuli" that channel attention to them, i.e. they determine which elements in a given situation will become salient. Of particular importance are then "behavior-initiating mechanisms" (Simon, 1947: 105) which can be used to influence what others will attend to and subsequently do. Ocasio's (1997) attention-based view provides a more detailed treatment of such behavior-initiating mechanisms in the form of structural factors. Specifically, his "attention-based view" sees organizations as "systems of distributed attentional processing" (Ocasio, 2011: 1290). It focuses specifically on structural factors that allocate attention to individual organizational 
members and thus, in turn, determine what these individuals will do. Later work by Joseph and Ocasio (2012) particularly identifies the crucial role of organizational architecture to the allocation and alignment of attention, where they define organizational architecture as "the structure of communications, interactions, and authority relationships across the organizational structure" (634). Ultimately, the structural distribution and allocation of attention will determine what decision-makers will do and thus "helps explain whether and how firms adapt to changing environments" (Ocasio, 1997: 204).

The strong emphasis on structural factors in distributing and allocating attention in the attention-based view put forth by Ocasio and colleagues downplays the role of individuals and their agency, i.e. the potential to use discretion by organizational members. In particular, Ocasio (1997) confines the role of individuals to being "players" that provide an "entrepreneurial function" in the allocation of attention in a top-down fashion (Ocasio (1997) notes that the most important players are the $\mathrm{CEO}$ and the top management group). Players may create or modify structure (e.g., through the creation of communication channels) and thus influence the behavior-initiating mechanisms. More importantly, however, he assumes that these behavior-initiating mechanisms in turn are effective in allocating attention to individual organization members, i.e. once created structure will indeed be relatively complete and effective in determining what organizational members do (see Ocasio's (1997) principle 2: situated attention), even though already Simon (1947) explicitly noted that individuals have personal goals that are not in line with higher-level organizational goals ${ }^{1}$. Generally, the role of individuals (which has been relatively neglected not only in the attention-based view but in later work building on the Carnegie tradition more generally;

\footnotetext{
${ }^{1}$ Interestingly, Simon (1947) introduces and discusses the notion and role of attention in a section with the headline "Purposive behavior in the individual"
} 
Gavetti, Levinthal, and Ocasio (2007)) may thus be important to allocating and distributing attention within an organization and thus to the question of adaptation more generally.

\section{Strategic initiatives, individuals and the hierarchy}

The question of the role of individuals in organizational adaptation is particularly relevant when it comes to the execution of strategic decisions, such as in the implementation of a strategic initiative, which are central to adapting to environmental changes. Specifically, strategic decisions are made in the face of uncertainty so that not all contingencies can be taken into account when making the decision (Klingebiel \& De Meyer, 2012). Thus, additional decisions will have to be made once the necessary information about contingencies is available, which may in turn have repercussions on the original, high-level decision (Siggelkow \& Rivkin, 2009). Typically, organizational members at lower levels of the hierarchy will be tasked with implementation of strategic decisions, i.e. there is vertical specialization of labor (Simon, 1947) and the distribution and allocation of attention to organizational members located within the organizational hierarchy will be important in determining how the strategic decision will be implemented.

Achieving coherence of decisions made during implementation, which are often made by managers at lower levels of the organization and require the cooperation of locally dispersed actors across the hierarchy over time, may be more difficult than achieving coherence in the initial decision (Cyert \& March, 1963). Jacobides (2007) argues that the organizational hierarchy provides mechanisms to help achieve coherence by allowing senior managers to rein in decisions made at lower levels, to impose common frames that help managers at lower levels to interpret issues, and to create and design the structures that guide managers at lower levels in the first place. This argument points to a key role for senior managers to properly design and manage the behavior-initiating mechanisms (or organizational architecture) so as to achieve effective implementation according to the original target set. However, as noted by 
Gavetti (2005), organizational members at lower level may be more knowledgeable about the specific issue they deal with than senior managers. In fact, decisions made at lower levels that run counter to decision made by senior managers earlier may even have a beneficial effect on the ultimate outcome of the initiative (Burgelman, 1994; Siggelkow \& Rivkin, 2009). Thus, an organization may be well served by lower level managers exercising discretion in making decisions about the implementation of a strategic initiative. Because ultimately the attention of lower-level managers will determine what they do and thus the types of decisions they make, understanding whether and how firms adapt to changing environments will require not only understanding the structural allocation and distribution of attention but also attentional agency by individuals, i.e. the role of individuals in distributing attention and in creating the structure that will guide attention, as well as the extent to which behavior-initiating mechanisms will in effect determine what individual organizational members do.

\section{THE STUDY AND METHODS}

An in-depth case study method (Eisenhardt, 1989; Yin, 2009) is ideally suited to empirically study the role of individuals in the implementation of a strategic initiative because it enables capturing the richness and complexity of the longitudinal processes involved and allows us to get close to the theoretical constructs and causal forces of interest (Siggelkow, 2007). However, such a study is a challenging endeavor due to the difficulty of getting access to data with the required level of granularity. We had unique access to rich data on the implementation of a particular strategic initiative and were able to track this initiative over its whole lifespan (a period of four years). Our focus on a single case is in line with recent qualitative studies that have examined single cases of strategic initiatives (Kaplan, 2008; Klingebiel \& De Meyer, 2012; Lovas \& Ghoshal, 2000). 


\section{Empirical context}

We studied the role of individuals in implementing a strategic initiative within the hierarchy of an established firm. Specifically, our study traced the efforts to build a new corporate venture within a large service company that has yearly revenues in the range of 1.52bn Euros and that operates in 15 European countries. The case firm is an established firm with a history dating back over a century. For most of its history, its business was confined mostly to its home country, where it enjoyed a monopoly position in its main business. Since the early 2000s this position has, however, come under attack through both increasing competition as well as substitution from new technologies and business models. Therefore the firm has invested substantial resources into establishing new businesses, which it also sought to internationalize. By 2007, the year our observations start, two new business groups had been established accounting for approx. $30 \%$ of corporate revenues, and approx. $20 \%$ of corporate revenues were obtained from international operations. Within this context, in January 2007 a new business unit within the traditional core business group was formed through the integration of three product groups that had been hitherto part of different business groups (but had a high overlap in terms of customers). The idea was that this business unit could later develop into a fourth corporate business group. In fact, at that time it was presented as one of three strategic areas of the company (the other two being the two new business groups).

Upon taking charge of the new business unit the head of the business unit quickly realized that it was impossible to develop an offering that would be competitive and that could be internationalized based on the product groups he had inherited (see Figure 1 for the organizational structure of the business unit and its position within the corporation). He thus initiated the new venture (that we study), which would be based on a to-be-developed technology platform and be targeted at the existing customers of the business unit. Altogether 
around 5 million Euros would be initially invested into building the platform. The business case projected revenues in the two-digit millions within 2-3 years and had a target of achieving 100 million in revenues within five years (part of this was supposed to come through acquisitions). The SVP of the business group supported the new venture as it fit with the business group level strategy of renewing the core business, and it was thus approved by the top management of the company. The work on developing both the technological platform and its commercialization started during summer 2008. The task of supervising these efforts was given to a head of new venture, who was hired in April 2008 (see Figure 2 for a timeline containing the key events of the new venture).

Insert Figure 1 about here

Insert Figure 2 about here

The original plan was to develop the technological platform in a way that it could easily be configured for any type of client and the setup for a particular client could be done within weeks. However, during the platform development project, the implementation of the platform started to diverge from the initial plan because the new venture team started to tailor the platform for a particular pilot customer. This led to substantial complexity and made it very difficult and time-consuming to implement the platform to other customers. Eventually, the persons responsible for customer implementations used other tools than the platform, thus making the platform obsolete. Ultimately, the original plan of a standard and configurable one-size-fits-all platform had turned into a capability of building unique and tailor-made solutions which was, however, very inefficient. 
The plan for commercialization was initially based on modularizing the platform (i.e. having standard components with a set of features and a fixed price list) and selling the modules through two dedicated managers. After these efforts had failed, a "solution sales" approach was adopted which entailed tailoring the offering to particular customer needs and "consulting" customers about how to take into use the platform. A lot of effort was put into developing sales competences through training and hiring new sales managers. Ultimately, very few clients could be convinced of buying the platform. However, there was more, yet limited success in selling other "solutions" that were based on other (substitute) technologies, i.e. technologies for the same purpose for which the platform was built.

The new venture had lost money throughout its history and never had been able to acquire a significant customer. Top management for a long time had not been aware of the venture's poor performance or the problems with the technological platform implementation. In fact, still in the end of 2010 they were optimistic about the prospects of the new venture. The head of business unit had been aware of the problems. He quit in the end of 2009. The head of the new venture was replaced in autumn 2010 because the new head of business unit believed that he did not have adequate skills for his job. In spring 2011, a new head of business group joined the company. He quickly noted the dire situation of the new venture and demanded a turnaround within one year. As that was judged impossible by the head of business unit, the new venture was shut down in summer 2011.

\section{Data collection}

Our study tracks the strategic initiative during the four years from venture initiation to venture closure. We relied on three sources of primary data: (1) interviews and (2) documents from inside and outside the case firm, and (3) direct observations. Altogether 27 interviews with managers across the hierarchy were performed at two points in time: 15 interviews were carried out in the period of April-October 2010 (out of which two with external cooperation 
partners). Because during the case analysis, within one year after carrying out the last interview, the firm had discontinued the venture, the authors went back into the field to also get insights on the period of 2010 to 2011. A second set of altogether 12 interviews was thus done between August and December 2012. While in the first round of interviews three levels of the hierarchy were covered, in the second round the additional layer of top management was added. Altogether the interviews spanned four levels of the organizational hierarchy of the case company, including top management; the management of the business unit; the management of the venture, the sales and the technology functions; and specific expert roles within these functions (see Table 1 for a summary of the interviewees). It is worth noting that much of our research took place concurrently with the new venture development efforts thereby mitigating concerns of retrospective recall biases. Interviews lasted from 30 minutes to 2 hours, consisted mostly of open-ended questions and followed a semistructured interview guide. Interviews where recorded and subsequently transcribed verbatim. In several cases, we clarified issues after the interview by phone calls, emails or informal discussions. As the understanding of the case had developed after the first round of interviews, in the second round we were able to ask more specific questions as well as probe for complementary information and fill gaps.

Insert Table 1 about here

The study also relied on the analysis of additional documents, such as memos, reports and presentations. Internal documents included minutes of meetings, business plans, reports to management, and other internal material as well as company publications such as annual reports, world wide web documents and sales presentations. These documents were utilized to establish timelines of events and triangulate information received from the interviews. 
One of the authors had the opportunity to closely observe the unfolding of events while being employed at the business unit in which the new venture was located (though not participating directly in the venture) from 2007 through 2010. This allowed close observation of events and provided first-hand insights especially into the early phases of the venture through participation in numerous formal and informal discussions with the persons involved with the venture at different levels of the hierarchy. To avoid potential biases arising from organization membership, all information and interpretations arising from these observations were documented and discussed in depth with the second author of this study who acted as a devil's advocate in interpreting these observational data.

\section{Data analysis}

The analysis combines standard procedures for case-based research (Eisenhardt, 1989; Huberman \& Miles, 1994; Miles \& Huberman, 1994) with the logic of analytical induction (Hicks, 1994; Joseph \& Ocasio, 2012). The underlying principle of our analysis was to firmly ground our emerging theory in data, but at the same time building on a broad theoretical framework based on the attention-based view (Joseph \& Ocasio, 2012; Ocasio, 1997, 2011) which specifically accounts for the role of attention structures and organizational architecture. In the analysis we rotated among data, literature, and emerging propositions moving gradually from description to explanation (Eisenhardt, 1989).

Specifically, we proceeded in two steps. As a first step of the analysis, a case history was written based on the first set of interviews. While writing the case history, it quickly became clear that there were incoherencies in the implementation of the new venture, and that attention to the initiative was subject to individual discretion. The interviews were thus coded using a list of initial codes based on the attention based view of the strategic management. These initial codes were supplemented by additional first-order codes that emerged from the data. In the next step we condensed the resulting list of codes and identified emerging 
relationships. The emerging patterns were contrasted with the literature in an iterative process (Strauss \& Corbin, 1998). A preliminary framework and a set of propositions were developed based on the first round of interviews. After the second round of interviews, the analysis was continued and the findings derived as presented in this paper.

\section{FINDINGS}

The new venture initiative deviated substantially from initial targets during the three-year course before it was shut down. We found that this was due to the interplay of incomplete governance channels", i.e. the formal and informal mechanisms set up by managers to provide the necessary information to guide their attention, and attentional agency", i.e. the exercise of discretion by managers over the distribution and allocation of attention of other organizational members, over time. While prior research in the attention-based view suggests a central role for organizational architecture and structure in guiding managerial attention, our evidence suggests that, given the complexity and uncertainty of strategic initiatives and the bounded rationality of organizational actors, governance channels are often incomplete in the sense that it is not possible to ex ante specify governance channels such a way that they would optimally allocate attention under all future contingencies, thereby leaving substantial latitude for managers to use discretion. We also find that attentional agency is not confined to the creation of structure and influencing the attention of others by central "players" (such as the CEO and the top management team), as asserted by Ocasio (1997), but that structure underdetermines behavior and thus individuals at all levels of the organization may exercise substantial discretion over where they focus attention. Part of such exercise of discretion is to exploit the incompleteness of governance channels by withholding or obfuscating information, leaving higher-level managers misinformed about the true state of the initiative at lower levels of the organization. Together attentional agency and incomplete governance channels lead to a situation where the issues and answers available to organizational members 
are based on prior instances of discretion by other individuals as well as the way governance channels had been created by superiors and exploited by managers at lower levels and, subsequently, the quality of attention on the new venture initiative turned out to be low. In the following, we provide a detailed account of our findings, first discussing attentional agency, followed by governance channels, and finally examining their interplay over time.

\section{Attentional agency: Individuals, the hierarchy and the allocation of attention}

The case data suggest that at any level of the hierarchy there were several initiatives that managers needed to attend to. These initiatives were not in conflict, but required the allocation of attention in order to be processed further and thus competed for attention. Specifically, across the three levels of the hierarchy for which we have data at each level there were two initiatives that have been consistently reported by the interviewees as competing for the attention of managers (with the new venture being one of them at every level). We found that there was substantial attentional agency both when it comes to the distribution of attention on these initiatives to other organizational members (through delegation and prioritization) and when it comes to the actual focus of attention on these initiatives (both in terms of how attention was distributed among initiatives as well as the specific issues and answers attended to within an initiative).

The hierarchy and initiatives requiring attention. The business group in which the new venture was hosted had annual revenues of close to $€ 1 \mathrm{bn}$, accounting for half the company’s revenues and most of the profits. It was a mature business, and because its competitive position was under threat a large efficiency improvement initiative was started in 2008 with investments of $€ 150 \mathrm{mio}$. and annual savings targets of $€ 80 \mathrm{mio}$. The investment into the new venture, which was started at about the same time, with $€ 5$ mio. was thus very small in comparison. However, the new venture was seen as the only growth business within the business group and a target had been set that it (together with acquisitions abroad) should 
contribute $€ 100$ mio. in annual revenues within 5 years. These two strategic initiatives thus competed for attention among the business group management and, in particular, the SVP in charge of the business group.

At the level of the business unit, there were three strategic initiatives, out of which one had been mostly delegated by the head of business unit to a more operational manager (and which was unrelated to the new venture). The other two were the new venture and the entry into a key international market. Both of these initiatives were central to achieving the aggressive growth targets of reaching $€ 100$ mio. in annual revenues (as noted by the head of business unit, "the idea was that [the new venture] is the thing that we will take to [international market] as well"). And both centrally depended on the head of business unit: The new venture was initiated by him and there was uncertainty as to how it would be executed, and the entry into the international market depended on his skills in finding and negotiating with potential acquisition target companies. So, the two strategic initiatives at the business unit level competed for the attention of the head of the business unit.

Finally, at the level of the new venture unit, apart from the focus on building the new venture the unit also got the responsibility for a range of existing products. Thus, rather than being able to focus exclusively on building the new venture, the existing products (which were mostly established products that were under competition and, in some cases, in mature or declining product markets) also competed for the attention of the managers in the new venture unit.

The attention devoted to the new venture by managers at different levels of the organizational hierarchy varied over time. Generally, when the new venture was started, managers at all levels of the hierarchy put a lot of attention on it. However, over time the focus of managers at higher levels on the new venture waned. According to the head of the business unit the SVP business group "was very much involved in the beginning, but he also 
had this big 150 million euro investment in the new [...] machines”. So the SVP business group shifted his attention to the efficiency improvement program over time. The head of business unit initiated the new venture, but later hired a venture manager from outside the company to take charge of it. So when he started to focus on the international market, he devoted less attention on the new venture and delegated the execution to the new venture manager. The new venture manager, finally, also delegated large parts of the execution to members of his team. At all three levels of the hierarchy managers chose to focus attention on the competing initiatives and so the time and effort spent on the new venture initiative decreased over time. In the following two sections we show how managers exerted attentional agency by (1) guiding the attention of others and (2) allocating attention within and among initiatives.

Guiding attention of others. At all levels of the hierarchy, we found that individual managers had substantial influence over where other managers would focus their attention. Specifically, by supplying and prioritizing initiatives, managers guided their subordinates to focus their attention on these initiatives (it should be noted that all managers had other operational duties and the initiatives required attention in excess of the basic effort on dealing with these operational duties). Such guidance involved both delegation (i.e., shifting responsibility and discretion in decision-making) and prioritization (i.e., setting limits to discretion). All initiatives were key items of the agendas of the management team meetings at the next-higher level of the hierarchy. At the business group level, both the efficiency improvement program and the new venture initiative were decided upon by the top management of the company and the SVP business group had the task to see that these initiatives would be implemented. Likewise, at the business unit level, there was pressure from the SVP business group on the head of business unit to both expand the business to the international market and to develop the new venture so to achieve the $€ 100$ mio. revenue 
target. At the level of the individual venture, the head of the new venture had the mandate to develop the technology around the new venture initiative and to commercialize it.

Superiors guided their subordinates' attention not only in terms of determining on which initiatives they should focus their time and effort, but also by setting broad priorities among these initiatives. For example, at the same time as the decision on starting the new venture was made the SVP business group emphasized the need to enter the international market quickly. As the head of business unit noted, "he said that [head of business unit], now you have to focus on [international market]". In this case it was understood that prioritizing one initiative over others would at the same time lead to lower availability of time and effort on other initiatives, so that prioritization on one level led to further delegation to the next lower level. As the head of the business unit stated, "the problem was that I was actually too high in the hierarchy of [the case company]. I had too much on the agenda, other things, because already the [new venture] was a full-time job, or should have been". Thus, the head of the business unit hired a manager dedicated to developing the new venture. This manager, in turn, was then tasked with overseeing the technology implementation platform and managing the commercialization.

In some cases superiors guided their subordinates' attention also in terms of how a specific initiative should be implemented, thus limiting discretion at lower levels. For example, when the technology implementation had been finalized but initial attempts at commercialization were unsuccessful, the SVP business group mandated a focus on commercialization even though the head of business unit raised serious concerns about the viability of the technology. The SVP stated that "now we need to move to the next step, try to live with the product we have and focus on commercializing and starting to sell it. That was the high-level brief I gave to [the new head of business unit]. Instead of using too much time for a huge development process inside the business, just create a package and communicate it [to customers]. 
Commercialize it". In other cases, however, managers allowed their subordinates much more leeway. For example, the SVP business group initially allowed substantial discretion over the implementation of the new venture. Specifically, he stated that "I gave quite free hands to my [business unit] management team, in particular [head of business unit] because I believe in this kind of management or leadership where somebody's fired up or geared up for something for which we have a common view".

Allocating attention within and among initiatives. In general, even though managers guided their subordinates both in terms of the initiatives they should attend to and the priorities among these initiatives, the amount of attention devoted by a manager to a particular initiative was not fully determined by the superior. Managers still had considerable discretion in terms of the attention put on the initiative, which they used in allocating the focus of their time and effort among the different initiatives as well as within particular initiatives, as we will show in the following.

In prioritizing among initiatives, we found that managers were also guided by personal characteristics and preferences. This led to a situation where these managers put less time and effort into a particular initiative than would have been required. For example, the SVP business group was characterized by the new venture manager as "so hectic [that] he doesn't really have time to concentrate on this and understand what is the real essence of the [new venture]'. In terms of the business unit, the SVP also shifted his attention to the international market market entry (and thus at the same time away from the new venture) because the other two business groups already had established a presence in that market. At the business unit level the head of business unit showed a clear preference for high level issues and delegated implementation and even follow-up of the implementation to others in the organization.

Managers may also choose among the activities necessary for executing a particular initiative (i.e. not whether to focus on a particular initiative but how they do so by attending to 
initiative-specific issues and answers). For example, the new venture manager and his team used substantial discretion in executing the new venture. The original objective in summer 2008 for the new venture was to build a one-size-fits-all technological platform that could be adapted to the needs of any customer of a certain size within a wide range of industries and that could be installed and be ready to use within 20-30 business days. In autumn 2008 the new venture team started the technology implementation project and signed up four pilot customers for which the platform would initially be set up. In the course of developing the technology platform, three of the pilot customer projects did not proceed, and the new venture team tried hard to make the technology work for the one remaining pilot customer. In doing so, as noted by an external consultant overseeing the implementation, "they started to change the scope of this thing, it changed so much that the whole vision went away from a universal system that could fit as an adaptor to any company and turned into basically [pilot customer]. The whole system, the whole investment became for one pilot. And it caused a lot of complexity for everyone". Because the pilot customer had very specific requirements, the platform later turned out to be unusable for most customer applications. Additionally to changing the platform specifications, the new venture team also failed to develop the technical skills needed to use the platform. The consultant stated that "in the end they were so desperate they started putting different people in different positions for the sake of putting somebody in that position. It's not gonna fly. There's not a single person that I was aware of when I left that knew how to [use the] platform. Not a single person". Furthermore, even though the commercialization of the new venture offering was among his key tasks, the new venture manager felt uncomfortable about it and thus delegated it to two managers in his team. The head of business unit thus stated: “what I didn't know was that [new venture manager] didn't know anything about selling, [he] wasn't a sales person at all. [...] He delegated [the sales] and the actual business conceptualization to [two solution sales 
managers]". Likewise, the new venture manager delegated the technology implementation project to a project manager.

Generally, when managers shifted their attention from one initiative to another they tended to delegate tasks within the initiative they chose to focus on less. Such delegation happened at all three levels of the hierarchy. For example, after approving the investment and the business plan for the new venture its execution was delegated down the hierarchy from the SVP business group to the head of business unit to the new venture manager who, in turn, delegated key parts of the implementation further to managers within his team. Such delegation may not turn out to be problematic, however, if superiors retain the ability to follow up the execution and intervene if necessary.

\section{Individuals, discretion and the incompleteness of governance channels}

We found that there were severe limitations in terms of superiors' ability to maintain attention and follow up the implementation of the new venture. This was because the governance channels and control systems (like management team meetings, reporting, or informal communication) that would help managers notice problems and focus their attention on them were incomplete. These channels were to a large extent created by the superiors (e.g., setting agendas for management team meetings). Interestingly, we also found that subordinates in several instances exploited these channels by misrepresenting or withholding information. As a result, some (though not all) superiors were essentially misinformed about the progress of the execution of the new venture and thus did not notice the severe problems that had occurred (in some cases for over two years after their occurrence), so that the incompleteness of the governance channels led to their malfunctioning.

Discretion and the failure of governance channels. Within the new venture, there were substantial changes against initial objectives, as noted above, which eventually led to incoherence with the original decision to start the new venture. Yet, no counter-measures 
were taken nor was it even realized by managers at higher levels of the hierarchy that such changes had actually taken place, which was, as we argue, the result of incomplete governance channels. Specifically, while attentional agency led to delegating tasks to managers further down in the organizational hierarchy, the governance channels that had been created by these managers that would have allowed following the progress of the initiative turned out to be malfunctioning.

It turned out that management had been essentially uninformed about the implementation of the technology platform and the dire state of the sales efforts despite the venture being a regular item on management team agendas and managers receiving reports from below. While the head of the business unit knew about the changes (as we will discuss below), his successor (who started in early 2010) upon taking charge sensed that there had been problems: "I understood that there were a lot of decisions that shouldn't have been made. [...] The [new venture technology] infrastructure, how it was configured [...] We realized that we were having a lot of quality problems all the time and then later on it was so difficult to fix anything". She continued: "I told [SVP corporate strategy] that something must be wrong but I don't know what'. The SVP business group, on the other hand, believed that he was indeed well informed about the venture's progress: "I would say that I was pretty well informed and we followed up constantly. We had in place a reporting rhythm and schedules where we saw how well we achieved the targets for different customer categories. We had identified the potential users of this kind of service and we were following up how new deals were coming in". He continued, however, stating that "within the more detailed problems that we had, within the operations itself I wasn't that much involved in that, that was more or less the [business unit's] management team's realm". The CEO was still enthusiastic about the new venture in the beginning of 2011, shortly before it was shut down as a failed case. The successor to the SVP business group, who started in early 2011, stated that "[the new venture] 
was introduced to me [by the CEO] as one of the most potential growth areas of [business group], so that this is the way to grow the business and earn a lot of money. [...] in the recruitment process [he said] this is THE growth area among the consumer services [...] the [new venture] was the crown jewel of the business.

Governance channels allow superiors to manage the discretion of their subordinates by controlling the execution of initiatives and alerting them to any divergence of the initiative against the objectives set at higher levels. This would allow superiors to counter such divergence or, alternatively, approve a change in direction if deemed necessary. The fact that managers at higher levels of the hierarchy were essentially uninformed about the state of the new venture initiative and were even drastically overoptimistic about its potential is a consequence of incomplete governance channels not providing the essential information to managers at higher levels of the hierarchy. In the following two sections, we shed light on the failure of governance channels by showing (1) how governance channels were created by managers and (2) how their incompleteness was exploited by lower-ranking managers.

Creating governance channels. The head of the business unit stated that "I was actually the only one in [case company] who had a picture of [the new venture] in the beginning". After delegating the execution of the new venture to the new venture manager he was well informed about the fact that the platform implementation project was changing direction. $\mathrm{He}$ had assigned a consultant to supervise the new venture team while he was focusing on the international market as, according to him, "[the consultant] knew the vision, because he was there building it from the beginning with me so he will be supervising [project manager] and also supervising [new venture manager]". He continued: "Already in August 2008 [American consultant] started to warn me. Everything is not going well. The guys are changing the business model." A governance channel created specifically for the venture and outside of the normal hierarchy thus provided the key information, whereas the "standard" governance 
channels related to the organizational hierarchy (like reporting and discussions in the management team meetings to which the managers supervising the venture belonged) were not important. However, the head of business unit chose not to intervene and take corrective actions because he was so involved in both the international market entry initiative and, at the same time, had a lot of operational tasks related to the existing business on the table. That is, he chose to use his discretion to focus attention on the international market despite the fact that the new venture would have needed his attention.

The SVP business group, on the other hand, was essentially misinformed about the progress of the new venture initiative (as was the rest of top management, as noted further below). The strategic initiatives of the business group were regularly discussed in the monthly management team meetings of the business group. There was detailed reporting on the progress of the efficiency improvement initiative, which provided facts as basis for discussion. However, no such detailed reports existed for the new venture platform implementation project and the discussions in the management team were thus based on the verbal reports provided by the head of business unit. According to the business development director of the business group, the reason for treating the initiatives differently was that "the [efficiency improvement] investment was something for everyone [whereas the new venture] was [head of business unit's] project and that unit was very separate from the others". As a consequence, there was little interest in developing dedicated governance channels to strictly follow up the progress of the new venture implementation project and the SVP business group never took notice of the fact that the technology implementation project had derailed from its original targets. The information passed in the existing governance channels, such as reports related to the sales process and the revenue generated, was often not useful for tracking the progress of the venture and rather led to misinformation and a false sense of progress. For example, the SVP business group believed that he was well informed about the venture's 
progress on the commercial side, as noted in the previous section In the end, he believed that the new venture was very close to breakthrough, stating that "I believe that in the end of the day, if we could have managed to convince and get the first real customer that would have built quite fast the confidence in the market that [case company] can produce these kinds of services. We just needed the big fish. The first one".

Exploiting governance channels. We found that subordinates in several instances strategically misrepresented or withheld crucial pieces of information. Specifically, they exploited the incompleteness of governance channels and provided information in a way that seemed satisfactory to the superior who set up the governance channel but that nevertheless concealed the real state of the initiative.

The head of business unit knew about the problems in the implementation of the new venture technology platform but did not mention them to the SVP business group nor were they discussed in the business group management team meetings. As the business development director of the business group said, "[head of business unit] was a bit protective. He really didn't want to expose that much what was happening [...] it was quite natural for him that, if nobody asked about this, then he wasn't that much pushing it either", thus exploiting the fact that the discussions in management meetings relied on verbal reports rather than facts.

The new venture manager was very opportunistic in terms of his communication with others. As noted by the business unit's sales director, "the main thing was that he looked good and numbers looked good and he had always someone to blame". Within the business unit's management team, the truth about the new venture progress was concealed. The business unit head stated that "in [the reporting to] the management team [the new venture] was developing well and everything was going according to plan". Even though he knew better, as noted above, the figures reported to the business unit management team were also reported to 
the SVP business group and the business group management team. When prompted about what the SVP business group had believed about the new venture the project manager of the implementation project later stated that "no wonder that he [SVP business group] thought that everything goes well, the sales pipeline he saw was always filled".

Another issue that made it hard to follow the development of the new venture was the fact that the revenues and profits for the new venture were not reported separately from the figures of the existing products that had been put under the responsibility of the new venture unit. One reason to put these products there was, as stated by the head of business unit, that "the [new venture] unit should have had some revenue. And this has to do with the fact that in big companies the problem is that if you don't show any revenue, you don't get any attention". The new venture unit reported its figures to the business unit, the business group and the corporate level divided into three segments that represented the three modules of the new venture offering, and each of the existing products had been assigned to one of the three modules.

\section{Languishing, problem fixing, and the inability to sustain attention}

Attentional agency through delegation and the use of decision-making discretion led to a situation where fundamental changes were made in the implementation of the new venture initiative that led to incoherence with the original strategic decision because it meant that the new venture initiative deviated substantially from its original scope and goals. At the same time, incomplete governance channels prevented managers at higher levels of the hierarchy from intervening and taking corrective action, either because they were essentially misinformed about the new venture or because their attention was focused on other initiatives and operational tasks. There is thus a close relationship between attentional agency and incomplete governance channels that helps to explain the eventual failure of the new venture 
as well as the fact that the dire state of the new venture came as a surprise to top managers three years after it had been started, as we discuss in the following.

Incoherence, drift and failure. The original scope and objective of the new venture project had been to build a one-size-fits-all platform that was fast to take into use, as stated by the head of business unit: "from the beginning we had this [vision] that in 30 working days [the platform] has to be up and running". The SVP business group and the head of business unit had exercised attentional agency by delegating the implementation of the initiative to the new venture manager with the implementation of the initiative. The new venture manager, in turn, had used discretion to implement a version of the technology platform that relied on extensive tailoring rather than standardization, noting that "of course we need to standardize them [customer cases] as much as possible, but talking about setup processes, they are more or less tailored". As a result, the decisions made by the new venture manager in implementing the initiative were incoherent with the original scope and objectives due to the interplay of attentional agency by managers at three levels of the hierarchy.

While attentional agency led to incoherence, the governance channels that had been set up should have led to directing attention on the issue of changing away from the original scope and vision and thus should have created the possibility to take corrective action. This corrective action could have either been to change the decision concerning the platform implementation or, alternatively, adapting the original objectives. The information about the incoherence indeed reached the head of business unit (through a dedicated governance channel outside the formal hierarchy: the consultant he had hired), who used his discretion not to take corrective action. It never reached other managers, in particular not top management, including the SVP business group because the governance channels that he had set up turned out to be malfunctioning (the information transmitted to him was incomplete and partly obfuscated). When asked whether he ever heard of problems in the platform implementation 
project, the SVP business group answered: “No, I didn't feel that or I can't recall that...I even believe that it was pretty well up and running." The incoherence in implementation was thus not resolved.

Because the SVP business group was essentially uninformed about the true state of the new venture, he mandated a focus on commercialization and sales from the successor to the head of business unit. This exercise of attentional agency was thus the result of the interplay of earlier exercises of discretion as well as the incompleteness of the governance channels set up by the SVP. Because the incoherence was never resolved, the new venture could in fact not sell the platform. So instead, the new venture team had to resort to tailoring the offering from other, existing products and services, leading the new venture to drift away from the original scope and objectives of a standard platform towards a business model of tailoring solutions to particular customer problems. According to a business manager, "We made the [new venture] plan much wider [...] so if we were solving a client problem which was [new venture]-like, it doesn't matter how we do it, then it's the right type of solution". As noted by the same manager: "there could be ten monkeys doing the thing and it could create value for the client. So the technology isn't the thing".

The interplay of attentional agency and incomplete governance channels had led to a drift of the new venture away from the original scope and objectives. Nevertheless, while the attention had shifted exclusively to selling tailored solutions the technology platform was kept up and running, which also meant that significant costs were incurred on a continuous basis (in terms of employees and license fees) without almost any revenues compensating for these costs. As the new SVP business group, who started in early 2011, noted: "[the new venture] was burning five million euros a year. Already at the end of 2011, the [new venture] had cost over 16 million euros losses and the plan, the forecast was that we would make four to five million euros losses every year for at least two years". Yet, even with the changed approach, 
as noted by the new SVP business group: "they had acquired rather small customers at the end of the day and it still took huge sales effort. But also the potential deals were surprisingly small'. The decision was thus made to shut down the platform and terminate the new venture.

Languishing and problem fixing. In the previous section we explained how the interplay of attentional agency and incomplete governance channels first led to incoherence and later to a drift in the scope of the new venture initiative and, ultimately, to its failure. What is surprising, however, is how long the new venture was allowed to languish, given the substantial losses it had made. In fact, even though the platform implementation project had started to deviate from the original scope already in autumn 2008, it took until spring 2011 for top management to realize that the initiative had gone off track and to demand corrective action. Whereas top management did not notice any problems, at the level of the business unit, the new head of business unit and her team sensed that there were problems but was unable to understand what exactly had gone wrong. The evidence suggests that the failure to take corrective action was thus two-fold: Incomplete governance channels led to a situation where at higher levels of the organization a problem was not noticed. At the same time, at lower levels of the organization it was not possible to understand or solve the problem. Impetus for taking corrective action only came when the head of business group changed and the new manager investigated the situation and demanded corrective actions.

The new head of business unit, upon taking charge, did notice that there had been a problem with the platform. However, she was unable to pinpoint the problem: "I wanted to have an [external] audit to be done in the company [...], but I didn't get the money for that. Then we decided to have an internal audit [but] nothing came out of that". Other members of the business unit management team were also wondering about the technology competences. For example, the business development director of the business unit said that "from my point of view, [the platform] was unreliable. They always say that it was down, that it didn't work. 
You could have these breaks in functionality in the system, just out of the blue. And I couldn't understand why. And I had this feeling that there were too few people who really understood how this system works". The inability to pinpoint the problem at the business unit level, together with the mandate to focus on commercialization rather than on fixing the technology, led managers in the venture to give up trying to solve the problem with the technology. Instead they focused on sales and solving customer problems with any technology and thus increased the scope of the type of customer projects that would count as new venture projects. According to a business manager, among the customer cases in 2010 and 2011 "I think there weren't cases where the platform was actually the thing".

Because of incomplete governance channels, top management was unaware of the dire situation of the new venture. As noted above, the SVP business group never took notice of the challenges in the technology platform implementation, though he believed to be wellinformed about the status and progress of the new venture. As a result, he had mandated a focus on commercialization of the new venture offering. That focus on commercialization indeed led to improvements in the figures that could be reported to top management, thus convincing top management further of being on the right path. Only when the new SVP business group joined the company in February 2011 was substantial corrective action initiated. Soon after starting he noted that "already after the first monthly report, I noticed [the losses] and I asked [new head of business unit] why do you make losses? [...] I found out that the Emperor didn't have any clothes. [...] I discussed with the CEO and he didn't know that the brutal facts were so brutal. It was compensated with other businesses". So, finally in summer 2011, four months after the new SVP business group took charge the platform was shut down, the employees laid off and the license contract cancelled. Thus, only when the top management finally took notice of the dire situation was corrective action taken and the new venture initiative was terminated. 


\section{DISCUSSION}

In this paper we provide in-depth insights into the interplay of attentional agency and incomplete governance channels during the implementation of strategic initiative. Our findings speak to theories of organizational attention, research on strategic initiatives, and provide a novel explanation for new venture failure. We discuss each of these in turn in the following.

\section{Organizational attention: Structure and agency}

While acknowledging that individuals may play a role in creating the behavior-initiating mechanisms (Simon, 1947) that determine attention and behavior within organizations, the attention-based view by (Ocasio, 1997) nevertheless emphasizes structural factors as antecedents to what organizational members attend to and do. Following Ocasio's (1997) conceptual work, there has been little empirical investigation into the question to what extent structure indeed determines attention and behavior and how pronounced the role of individual agency and discretion is compared to the influence of structural factors. The findings that we presented above suggest that individual agency plays a larger role than suggested by Ocasio (1997). In particular, while we find that managers at higher levels of the hierarchy guide the attention of others and create structure in the form of, for example, governance channels (i.e., in Ocasio's word, managers act as "players"), we find evidence for additional mechanisms of individual discretion. For example, in violation of Ocasio's "principle 2: situated attention" managers at lower levels do not mechanistically respond to the stimuli provided to them by the behavior-initiating mechanisms but their attention is essentially underdetermined by structure (Felin \& Foss, 2011; Levinthal \& Rerup, 2006). Thus, what managers do may be to a considerable extent shaped by factors outside the specific behavior-initiating mechanisms, such as personal beliefs or preferences, which introduces an additional element of variance in behavior within organizations. 
Additionally, the case findings suggest that the role of structural positions, which Ocasio (1997) sees as "provid[ing] for a system of hierarchical authority in organizations that allows conflicts over subunit goals to be resolved and resources to be mobilized", may not work as asserted by Ocasio. Specifically, because governance channels may often be incomplete, the vertical division of labor (Jacobides, 2007) may be ineffective in resolving incoherencies between goals at different levels of the organization. As had happened in our case, the use of discretion at lower levels of the hierarchy together with the incompleteness of the governance channel to follow up what lower-level managers do, may lead to a situation where incoherence is not resolved immediately. In such situations, if the inconsistency leads to a problem, managers trying to make sense of that problem about which they lack crucial information may produce new issues or answers endogenously. Alternatively, they may focus their attention on particular issues or answers (and subsequently guide others towards these) because incomplete governance channels preclude them from seeing a more comprehensive set of issues and answers. This implies a reciprocal relationship between attentional agency and incomplete governance channels over time in which individuals use discretion over the issues and answers they work with and, at the same time, the set of issues and answers in any given situation is subject to prior use of discretion by individuals and the way in which governance channels have been created by superiors on the one hand and exploited by managers at lower levels of the hierarchy on the other hand.

For the attention-based view our findings suggest that organizations' ability to adapt is not only based on how they enact their environment (Ocasio, 1997; Weick, 1979), with interpretations translated into structure that quasi-automatically determines attention and behavior, but that there is a strong role for individual agency at all levels of the organization that mediates the relationship between enactment and the ensuing behavior-generating stimuli and the resulting behavior (Felin \& Foss, 2011). Furthermore while individual agency and 
discretion are sources of variance in terms of attention and behavior, their consequences on adaptation are made more complex through their interplay with incomplete governance channels across the hierarchy over time.

\section{Implementation of strategic initiatives}

The implementation of a strategic initiative requires coherent decisions to be made by managers at lower levels (Dvir \& Lechler, 2004; Pitsis et al., 2003). Our findings suggest that attentional agency and incomplete governance channels pose limits to the coherence of lowerlevel decisions with the original scope and objectives of an initiative. The fact that such incoherencies may remain undetected for considerable time has important implications for the performance of strategic initiatives as well as their scope and their eventual termination if they turn out to have failed.

As we find in our study, the reciprocal relationship between attentional agency and incomplete governance channels that we noted in the previous section may lead to the strategic initiative drifting away from the initial scope and objectives. Because an unresolved incoherence precluded the venture from using the technology platform and at the same time top management, being uninformed about the incoherence, had guided managers within the business unit and the venture towards focusing on commercialization, the new venture initiative substantially changed course. For managers at higher levels in the hierarchy, due to incomplete governance channels such drift arising from attentional agency and incoherencies may be indistinguishable from beneficial adaptation due to learning (Siggelkow \& Rivkin, 2009). Thus, because the causes of drift and changes in course are obscured from top managers, strategic initiatives may languish and, rather than being terminated because of failing to reach their objectives, be sustained and even receive additional funds. Our findings thus also provide an alternative explanation for why firms fail to terminate failing initiatives (Ross \& Staw, 1986; Sleesman et al., 2012). 
One may argue that in the new venture initiative we studied avoiding the problems we noted above and keeping coherence in the implementation of a strategic initiative would have required attentional engagement, i.e. the "intentional and sustained allocation of cognitive resources to guide problem solving, planning, sensemaking, and decision making" (Ocasio, 2011: 1288). However, both the fact that governance channels had been set up for the new venture (e.g., there were regular reports and frequent discussions in the business group management team) and the argument in the previous paragraph about the possible inability to distinguish between drift and learning points to the importance of quality of attention rather than quantity (Weick \& Sutcliffe, 2006). Specifically, because vertical division of labor and specialization is inevitable in implementing strategic initiatives, managers at higher levels must see that they install proper governance mechanisms that guarantee a high level of quality of attention (Jacobides, 2007). The fact that in the new venture the consultant installed as governance channel by the head business unit manager was effective in providing timely and accurate information suggests a potential superiority of informal governance channels (such as, for example, "management by walking around; Peters and Waterman (1982)) in bringing about high-quality attention.

\section{Attention and corporate venture failure}

Adding to a small literature that analyzes corporate venture failure (Keil et al., 2009; Shepherd, Covin, \& Kuratko, 2009; Shepherd, Haynie, \& Patzelt, 2013; Thornhill \& Amit, 2003), which suggests that the great majority of new business ventures in established firms fail to achieve their objectives (Campbell \& Park, 2004; Stevens \& Burley, 1997), our results provide insights into corporate venture failure from an attention-based perspective. Prior literature argues that governance mechanisms, for example top management support, are crucial to the performance of a corporate venture (Garrett \& Neubaum, 2013). Our findings suggest that top management support for a particular corporate venture may be limited due to 
other initiatives competing for scarce attention. However, as noted in the previous paragraph, what may be even more important than the amount of attention devoted to a corporate venture is the quality of attention that the venture receives (Weick \& Sutcliffe, 2006). Thus, new ventures may fail not because they do not receive support from top management but because they receive the wrong kind of support, due to top management essentially being uninformed about the true state of the venture and thus being unable to make decisions that would increase the chances of new venture success. Consequently, the potential to use discretion as well as the way in which governance channels are set up may turn out to be crucial to the performance of corporate ventures.

\section{Limitations and future research}

We acknowledge several limitations of our research. Given that we focused on an in-depth investigation of the implementation of a strategic initiative in a single organization situated in a single industry and country, the generalizability of our results naturally are a concern. To relieve concerns about idiosyncrasy of findings and specificity to a particular context, industry or country, future research should test our arguments using quantitative studies that would consist of multiple industries and multiple countries. Our above discussion also points to several areas worth of study. For example, more research is needed on the role of individuals in generating variance in behavior and their characteristics that shape how organizations adapt to environmental changes and implement strategic initiatives. Furthermore, one may investigate how quality of attention may be achieved by examining what governance channels are more or less effective in allowing managing incoherencies in implementation, or avoiding them in the first place. Finally, the role of governance and quality of attention and their effect on corporate venture success may be examined. 


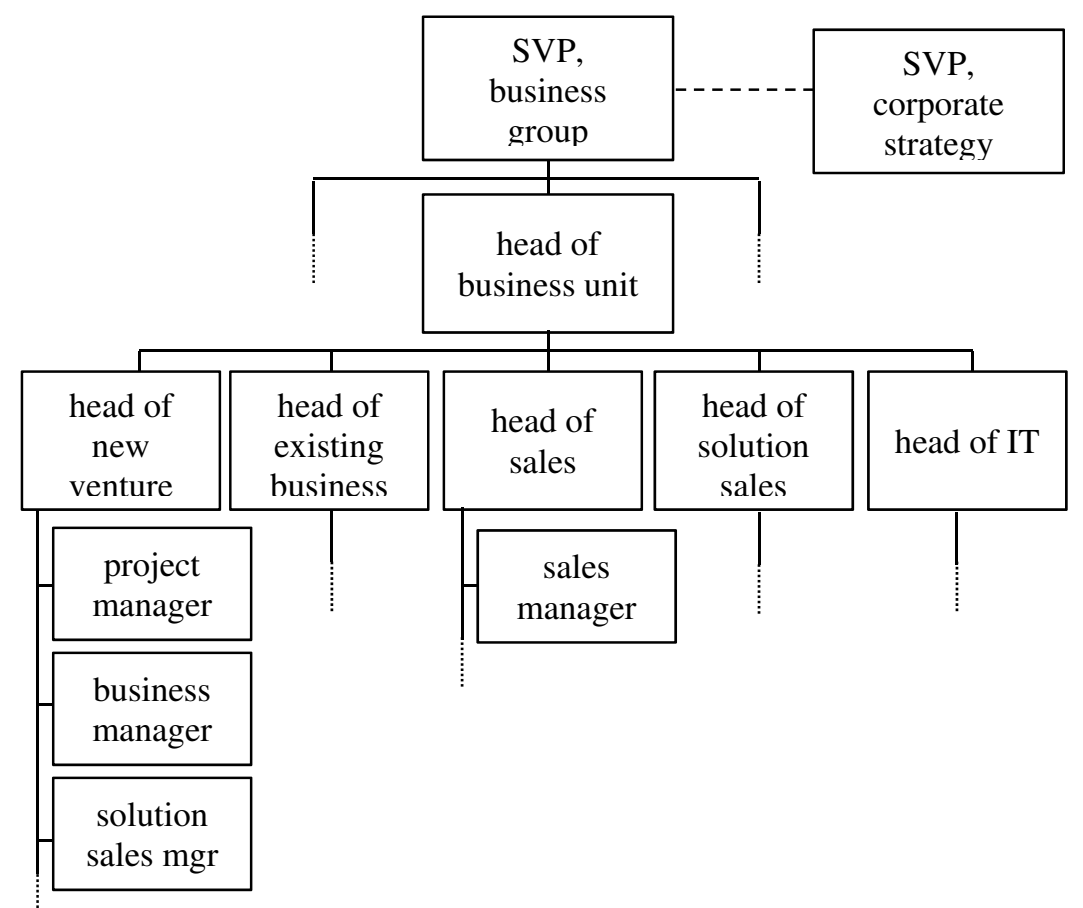

Figure 1. Organizational structure of the business unit

2007 January: new business unit formed through integration of three separate businesses within the parent company

October: head of business unit visits United States; presents idea of new venture to business group management upon return

2008 April: head of new venture hired; approval for investment in platform development

June: platform development starts, scheduled completion February 2009; parallel development of commercial model

September: cooperation with pilot customers starts

2009 January: sales partnership with consulting company agreed

February: planned platform launch; platform not ready but launched

"silently" (to selected customers); sales efforts begin

June: sales partnership with consulting company ended

October: dedicated unit to commercialize platform formed

December: head of business unit resigns and leaves company

2010 January: 2009 parent company EBIT has declined by over 50\% as compared to previous year; business group EBIT shrank by $25 \%$

February: new head of business unit starts

September: head of new venture resigns; new head appointed; dedicated unit to commercialize platform discontinued

October: head of business group (superior of head of business unit) resigns

2011 January: 2010 parent company EBIT has declined by another 50\%; business group EBIT shrank by $10 \%$

February: new head of business group starts; demands new venture to be profitable within 12 months

June: announcement that new venture will be shut down

Figure 2. Timeline of the venture 


\begin{tabular}{|l|l|l|l|}
\hline Position & Tenure & $\mathbf{2 0 1 0}$ & $\mathbf{2 0 1 2}$ \\
\hline SVP, corporate development & throughout & & 1 \\
\hline SVP, head of business group (beginning) & until Jun. 2010 & & 1 \\
\hline SVP, head of business group (later)+ & from Oct. 2010 & & 1 \\
\hline head of business development, business group & until Feb. 2010 & & 1 \\
\hline head of business unit (beginning) & until Dec. 2009 & 1 & 1 \\
\hline head of business unit (later) & from Feb. 2010 & & 1 \\
\hline head of new venture (beginning)+ & until Aug. 2010 & 2 & \\
\hline head of new venture (later)* & from Sep. 2010 & 1 & 1 \\
\hline head of sales & from Aug. 2008 & 1 & 1 \\
\hline project manager, head of solutions \& concepts unit** & throughout & 2 & 1 \\
\hline head of business development & from May 2010 & & 1 \\
\hline head of IT & throughout & 1 & \\
\hline marketing manager & throughout & 1 & \\
\hline product manager & throughout & 1 & \\
\hline solution sales manager & throughout & 1 & \\
\hline sales manager++ & from Jan. 2009 & 1 & \\
\hline key account sales manager & throughout & 1 & \\
\hline customer process manager+ & from Nov. 2009 & & 1 \\
\hline customer delivery manager & from Jan. 2009 & & 1 \\
\hline external consultant & - & 1 & \\
\hline partner, sales partnership company & - & 1 & \\
\hline TOTAL & & $\underline{15}$ \\
\hline
\end{tabular}

*was head of IT until Jul. 2009 and head of existing business from Aug. 2009 to Aug. 2010

**was project manager until Sep. 2009, head of solutions \& concepts unit from Oct.2009

+was hired from outside of the case company

++ joined the case company through an acquisition

Table 1. List of interviewees 


\section{REFERENCES}

Bower, J. L. 1970. Managing the resource allocation process. Boston, Mass.: Harvard Business School Press.

Burgelman, R. A. 1983. A model of the interaction of strategic behavior, corporate context, and the concept of strategy. Academy of Management Review, 8(1): 61-70.

Burgelman, R. A. 1994. Fading memories: A process theory of strategic business exit in dynamic environments. Administrative Science Quarterly, 39(1): 24-56.

Campbell, A., \& Park, R. 2004. Stop Kissing Frogs. Harvard Business Review, July-August: 27-28.

Cyert, R. M., \& March, J. G. 1963. A Behavioral Theory of the Firm. Englewood Cliffs, NJ: Prentice-Hall.

Dvir, D., \& Lechler, T. 2004. Plans are nothing, changing plans is everything: the impact of changes on project success. Research Policy, 33(1): 1-15.

Eisenhardt, K. M. 1989. Building Theories from Case Study Research. Academy of Management Review, 14(4): 532-550.

Emirbayer, M., \& Mische, A. 1998. What is agency? American Journal of Sociology, 103(4): 962-1023.

Felin, T., \& Foss, N. J. 2011. The endogenous origins of experience, routines, and organizational capabilities: the poverty of stimulus. Journal of Institutional Economics, 7(2): 231-256.

Garrett, R. P., \& Neubaum, D. O. 2013. Top Management Support and Initial Strategic Assets: A Dependency Model for Internal Corporate Venture Performance. Journal of Product Innovation Management, 30(5): 896-915.

Gavetti, G. 2005. Cognition and hierarchy: Rethinking the microfoundations of capabilities' development. Organization Science, 16(6): 599-617.

Gavetti, G., Levinthal, D., \& Ocasio, W. 2007. Neo-carnegie: The carnegie school ' s past, present, and reconstructing for the future. Organization Science, 18(3): 523-536.

Heugens, P. P. M. A. R., \& Lander, M. W. 2009. STRUCTURE! AGENCY! (AND OTHER QUARRELS): A META-ANALYSIS OF INSTITUTIONAL THEORIES OF ORGANIZATION. Academy of Management Journal, 52(1): 61-85.

Hicks, A. 1994. Qualitative comparative analysis and analytical induction: the case for the emergence of the social security state. Sociological Methods and Research, 23(1): 86113.

Huberman, A. M., \& Miles, M. B. 1994. Data management and analysis methods. In N. K. Denzin, \& Y. S. Lincoln (Eds.), Handbook of qualitative research: 428-444. Thousand Oaks: Sage.

Jacobides, M. G. 2007. The inherent limits of organizational structure and the unfulfilled role of hierarchy: Lessons from a near-war. Organization Science, 18(3): 455-477.

Joseph, J., \& Ocasio, W. 2012. Architecture, attention, and adaptation in the multibusiness firm: General electric from 1951 to 2001. Strategic Management Journal, 33(6): 633660.

Kaplan, S. 2008. Framing Contests: Strategy Making Under Uncertainty. Organization Science, 19(5): 729-752.

Keil, T., McGrath, R. G., \& Tukiainen, T. 2009. Gems from the ashes: Capability creation and transformation in internal corporate venturing. Organization Science, 20(3): 601620.

Klingebiel, R., \& De Meyer, A. 2012. Becoming Aware of the Unknown: Decision Making During the Implementation of a Strategic Initiative. Organization Science: in print. 
Lechner, C., \& Floyd, S. W. 2012. Group influence activities and the performance of strategic initiatives. Strategic Management Journal, 33(5): 478-495.

Levinthal, D., \& Rerup, C. 2006. Crossing an apparent chasm: Bridging mindful and lessmindful perspectives on organizational learning. Organization Science, 17(4): 502513.

Lovas, B., \& Ghoshal, S. 2000. Strategy as guided evolution. Strategic Management Journal, 21(9): 875-896.

Miles, M. B., \& Huberman, A. M. 1994. Qualitative data analysis: An expanded sourcebook (2nd ed.). Thousand Oaks, CA: Sage.

Ocasio, W. 1997. Towards an attention-based view of the firm. Strategic Management Journal, 18: 187-206.

Ocasio, W. 1999. Institutionalized action and corporate governance: The reliance on rules of CEO succession. Administrative Science Quarterly, 44(2): 384-416.

Ocasio, W. 2011. Attention to Attention. Organization Science, 22(5): 1286-1296.

Peters, T. J., \& Waterman, R. H. 1982. In Search of Excellence: Lessons from America's Best-Run Companies. New York: Harper \& Row.

Pitsis, T. S., Clegg, S. R., Marosszeky, M., \& Rura-Polley, T. 2003. Constructing the Olympic dream: A future perfect strategy of project management. Organization Science, 14(5): 574-590.

Ross, J., \& Staw, B. M. 1986. Expo 86: An Escalation Prototype. Administrative Science Quarterly, 31(2): 274-297.

Shepherd, D. A., Covin, J. G., \& Kuratko, D. F. 2009. Project failure from corporate entrepreneurship: Managing the grief process. Journal of Business Venturing, 24(6): 588-600.

Shepherd, D. A., Haynie, J. M., \& Patzelt, H. 2013. Project Failures Arising from Corporate Entrepreneurship: Impact of Multiple Project Failures on Employees' Accumulated Emotions, Learning, and Motivation. Journal of Product Innovation Management, 30(5): 880-895.

Siggelkow, N. 2007. Persuasion with case studies. Academy of Management Journal, 50(1): 20-24.

Siggelkow, N., \& Rivkin, J. W. 2009. Hiding the Evidence of Valid Theories: How Coupled Search Processes Obscure Performance Differences among Organizations. Administrative Science Quarterly, 54(4): 602-634.

Simon, H. A. 1947. Administrative behavior. New York: Macmillan.

Simon, H. A. 1996. The sciences of the artificial (3rd edition ed.). Cambridge, MA: MIT Press.

Sleesman, D. J., Conlon, D. E., McNamara, G., \& Miles, J. E. 2012. Cleaning up the Big Muddy: A Meta-analytic review of the determinants of excalation of commitment. Academy of Management Journal: in print.

Stevens, G. A., \& Burley, J. 1997. 3000 raw ideas - 1 commercial success! Research Technology Management, 40(3): 16-27.

Strauss, A., \& Corbin, J. 1998. Basics of qualitative research (2nd ed.). Thousand Oaks, CA: Sage.

Thornhill, S., \& Amit, R. 2003. Learning about failure: Bankruptcy, firm age, and the resource-based view. Organization Science, 14(5): 497-509.

Weick, K. E. 1979. The social psychology of organizing (2nd ed.). Reading, Mass.: AddisonWesley.

Weick, K. E., \& Sutcliffe, K. A. 2006. Mindfulness and the quality of organizational attention. Organization Science, 17(4): 514-524.

Yin, R. K. 2009. Case study research: Design and methods. London, UK: Sage Publications. 